\title{
Development and Validation of a COPD Self-Management Scale
}

\author{
Caihong Zhang PhD, Weihong Wang PhD, Jiping Li PhD, Xiaoxia Cai PhD, \\ Hua Zhang MD, Haihua Wang MD, and Xiuhua Wang PhD
}

\begin{abstract}
BACKGROUND: Although self-management reportedly can improve the health and quality of life of patients with COPD, there is no validated instrument for evaluating the status of the selfmanagement of patients with COPD. METHODS: A 51-item COPD Self-Management Scale (CSMS), including 5 domains (symptom management, daily life management, emotion management, information management, and self-efficacy), was developed and validated, using data from 413 COPD subjects. RESULTS: The CSMS showed good reliability and validity in the validation study. The test-retest correlation coefficient and Cronbach alpha coefficient of the CSMS were 0.87 and 0.92 , respectively. The content validity index of the CSMS was 0.90 . The correlations of the CSMS with the established COPD Self-Efficacy Scale, Chronic Disease Self-Management Behavior Scale, and Chronic Disease Self-Efficacy Scale were $0.71,0.61$, and 0.66, respectively. The self-efficacy domain in the CSMS was highly correlated with the total score of the COPD Self-Efficacy Scale (correlation coefficient $=\mathbf{0 . 8 2}$ ) and the Chronic Disease Self-Efficacy Scale (correlation coefficient $=\mathbf{0 . 7 6}$ ). Moreover, the total score of the CSMS was negatively correlated with percent-of-predicted FEV $\left(\mathrm{FEV}_{\mathbf{1}} \%\right)$, with a correlation coefficient of $\mathbf{- 0 . 5 5}$. The CSMS symptom management domain and daily life management domain had relatively high correlation coefficients $(-0.57$ and -0.64 , respectively) with $\mathrm{FEV}_{1} \%$, indicating good criterion validity of the scale. CONCLUSIONS: The CSMS is reliable, valid, and sensitive for evaluating the self-management status of COPD patients. To our knowledge, it is the first dedicated scale for evaluating the self-management status of COPD patients, and will serve as an important instrument for assessing and improving the self-management of COPD patients, particularly, those in the Hunan region of China. Key words: COPD; self-management; validity; reliability; validation study; self-efficacy. [Respir Care 2013;58(11):19311936. (c) 2013 Daedalus Enterprises]
\end{abstract}

\section{Introduction}

COPD is characterized by a progressive deterioration of lung function and is associated with mental and physical comorbidities such as depression, muscle wasting, and heart

\footnotetext{
The authors are affiliated with the International School of Nursing, Hainan Medical College, Haikou, Hainan, China, with the exception of Weihong Wang PhD, who is affiliated with the Department of Nursing, Hunan Normal University, Changsha, Hunan, China, and Xiuhua Wang PhD, who is affiliated with the School of Nursing, Central South University, Changsha, Hunan, China.
}

This work was supported by the Health Bureau of Hainan Province (\#2009-40).

Supplementary material related to this paper is available at http:// www.rcjournal.com. failure. ${ }^{1}$ COPD imposes an enormous burden on patients, healthcare professionals, and society. ${ }^{2,3}$ The burden of COPD in China is currently greater than that found in developed countries. A population-based, cross-sectional survey of COPD conducted between 2002 and 2004 showed that the overall prevalence of the disease in people $>40$ years old was $8.2 \%,{ }^{4}$ which would result in a COPD patient population of more than 43 million in China during that time period. It has been reported that self-management of patients with COPD can change the patient's lifestyle,

\footnotetext{
Correspondence: Xiuhua Wang PhD, School of Nursing, Central South University, 172 Tongzipo Road, Changsha, Hunan 410013, China. Email: xiuhua203@163.com.
}

DOI: $10.4187 /$ respcare.02269 
reduce costs of hospitalization, and improve the patient's depression and quality of life. ${ }^{5-7}$ However, there is no dedicated scale for evaluating the status of the selfmanagement of patients with COPD. In the present study we developed and validated a self-management scale for COPD patients, which provides an important instrument for assessing and improving the self-management of COPD patients.

\section{Methods}

This study was approved by the ethics committee of Central South University, Changsha, Hunan, China. Written informed consent was obtained from all subjects before participation.

\section{Subjects}

From August 2008 to December 2008, a source-stratified (in-patient and out-patient) random sample of subjects, who required treatment or a physical examination in different hospitals of Hunan Province, was drawn from eligible COPD patients. The inclusion criteria were a confirmed diagnosis of COPD, according to standard criteria, ${ }^{8}$ and disease duration of $\geq 1$ year. The exclusion criteria were severe cognitive impairment, concurrent oncologic or psychiatric disease, or drug or alcohol abuse. Of 413 COPD Self-Management Scale (CSMS) forms distributed, $274(66.3 \%)$ were returned from in-patients (mean \pm SD age $67.5 \pm 13.28 \mathrm{y}$ ), and $139(33.7 \%)$ from out-patients (mean \pm SD age $66.9 \pm 11.71 \mathrm{y}$ ). Of the 413 subjects, 120 were randomly selected to complete a second test with the CSMS 2 weeks later, and 150 were randomly selected to complete tests with the COPD Self-Efficacy Scale (CSES), ${ }^{9}$ the Chronic Disease Self-Management Behavior Scale (CDSMBS), ${ }^{10}$ and the Chronic Disease Self-Efficacy Scale (CDSES). ${ }^{11}$ Basic characteristics of the subjects are shown in the supplementary materials at http://www.rcjournal. com.

\section{Conceptual Framework}

Based on the definition of self-management by Corbin and Straus, ${ }^{12}$ and the description of self-management contents for COPD patients by Worth et al, ${ }^{13}$ COPD selfmanagement was defined as the process in which COPD patients change their lifestyles and develop self-efficacy through managing COPD symptoms, treatments, and physiological and psychological changes. Five conceptual domains of COPD self-management were identified: symptom management, daily life management, emotion management, information management, and self-efficacy. Symptom management refers to the COPD patient seeking medication and others' help to deal with COPD symptoms

\section{QUICK LOOK}

\section{Current knowledge}

COPD is characterized by a progressive deterioration of lung function, and is associated with mental and physical comorbidities. COPD imposes a substantial burden on patients and the healthcare system. COPD selfmanagement improves quality of life, but there is no validated instrument for evaluating COPD self-management.

\section{What this paper contributes to our knowledge}

A new 51-item COPD Self-Management Scale, which includes 5 domains (symptom management, daily life management, emotion management, information management, and self-efficacy) is reliable, valid, and sensitive for evaluating COPD self-management.

such as dyspnea, cough, and sputum. Daily life management refers to the COPD patient taking an appropriate amount of exercise and avoiding activities that exacerbate COPD. Emotional management refers to the COPD patient managing emotional changes such as anxiety and depression associated with COPD. Information management refers to the COPD patient communicating with clinicians or accessing media to gain information about COPD. Selfefficacy refers to the confidence of the COPD patient in self-management of symptoms, daily life, emotions, and information.

\section{Scale Development}

Programmed decision processing, a method to develop a scale by a nominal group and a focus group, was used. A pool of 90 items was drafted by interviewing the nominal group, consisting of 20 COPD subjects. The focus group, consisting of 9 experts in psychology, nursing, social science, pulmonary medicine, biostatistics, and epidemiology, reviewed and discussed the pool of items. Individual questions were edited to ensure that problematic items were identified and redundant questions eliminated before an initial pool of 67 items was drafted. The responses to each item were graded on a 5-point scale $(1=$ never, $2=$ rarely, $3=$ sometimes, $4=$ often, and $5=$ always). A pilot test was conducted in 30 subjects, and the scale items were readjusted according to the answers received. Then a test was conducted in 413 COPD subjects, as mentioned above, in which the scale items were selected by the following statistical methods. First, subjects were ranked by the score on the scale to derive a high- and low-score group, comprising $27 \%$ of those with 


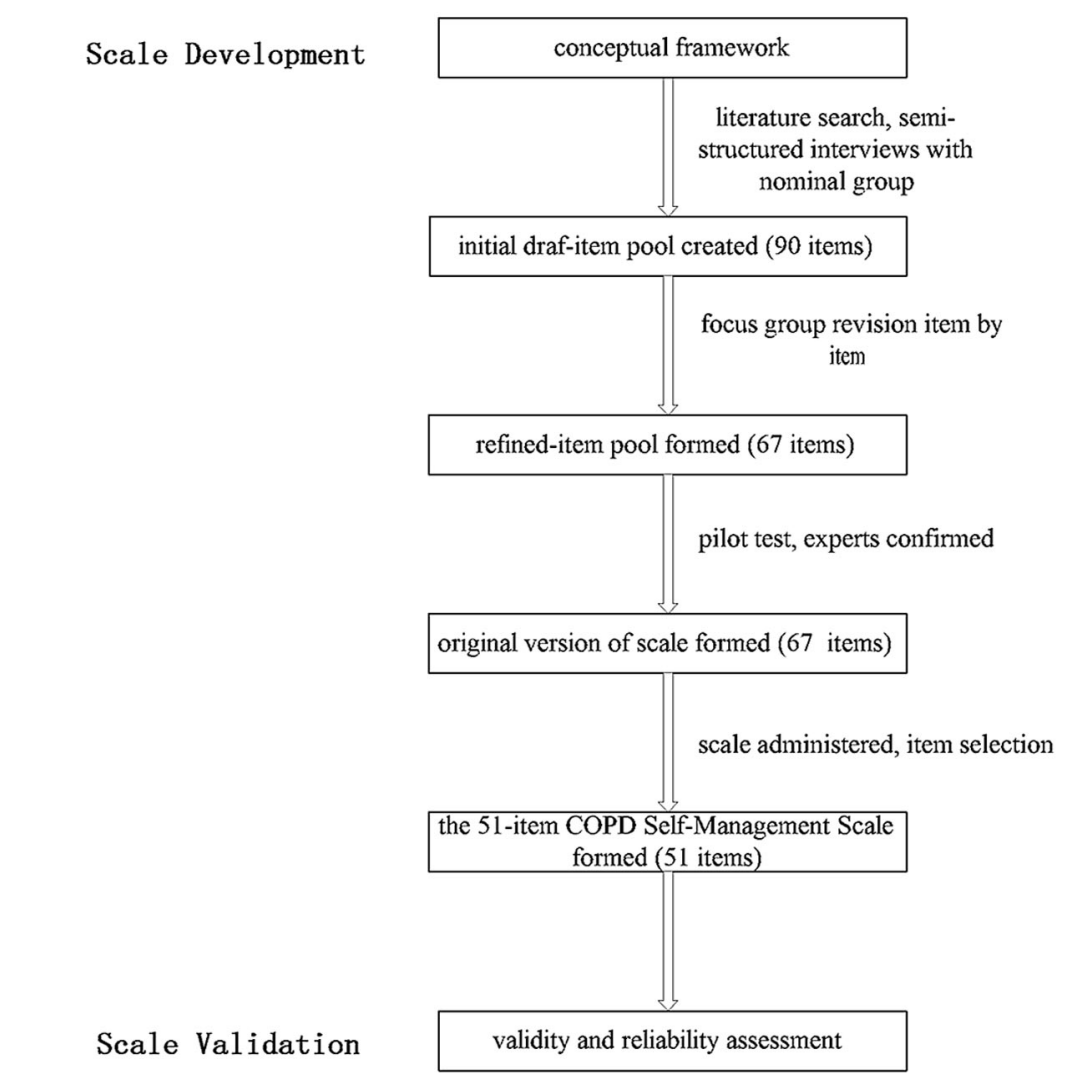

Fig. 1. Flow chart for the development process of the COPD Self-Management Scale.

the highest and lowest scores, respectively. The score of each item was then compared using the Student $t$ test. Items with no significant difference $(P=.01)$ between the groups were eliminated. Second, any item with a Pearson correlation coefficient $<0.30$ with the total scale score was eliminated. Any item correlating with more than 2 domains with a correlation coefficient $>0.40$ were also eliminated. After the screening tests, 11 items were discarded. The remaining 56 items were subject to principal components analysis, which was used to eliminate items with a factor loading $<0.4$. A 51 -item CSMS was finally derived after the factor analysis (see the supplementary materials at http://www.rcjournal.com).

\section{Scale Validation}

The correlation coefficients were calculated for the first and third week tests for test-retest reliability. Internal consistencies for the instrument and its domains were calculated with the Cronbach alpha coefficient. The validity of the CSMS was tested in 3 aspects. Content validity was evaluated using the standard proposed by Lynn for content validity index (>0.78). ${ }^{14} \mathrm{We}$ used principal components analysis and correlation analysis to test construct validity.
For criterion validity, 4 criteria were used, including the CSES, the CDSMBS, the CDSES, and the percent-ofpredicted $\mathrm{FEV}_{1}\left(\mathrm{FEV}_{1} \%\right)$. All statistical analyses in this study were performed with statistics software (SPSS 13.0, SPSS, Chicago, Illinois). The significance level of this study was set at 2 -sided alpha $=.05$. The main procedure of the study is shown in Figure 1.

\section{Results}

As mentioned in the Methods section, after screening with the Student $t$ tests and correlation analyses, 11 items were eliminated from the initial draft pool of 67 items. Principal components analysis with varimax rotation was subsequently performed to determine the underlying factor structure of the 56-item CSMS and whether items should be removed. The Kaiser-Meyer-Olkin measure of sampling adequacy was 0.85 , which would be considered meritorious by Kaiser. ${ }^{15}$ The results of the Bartlett test indicated that there were significant correlations among the 56 items (chi-square $=11,389.61, P<.01$ ), supporting the factorability of the correlation matrix. Criteria for inclusion of an item on a factor were a minimum loading of 0.40 and at least 0.10 difference from other loadings. 


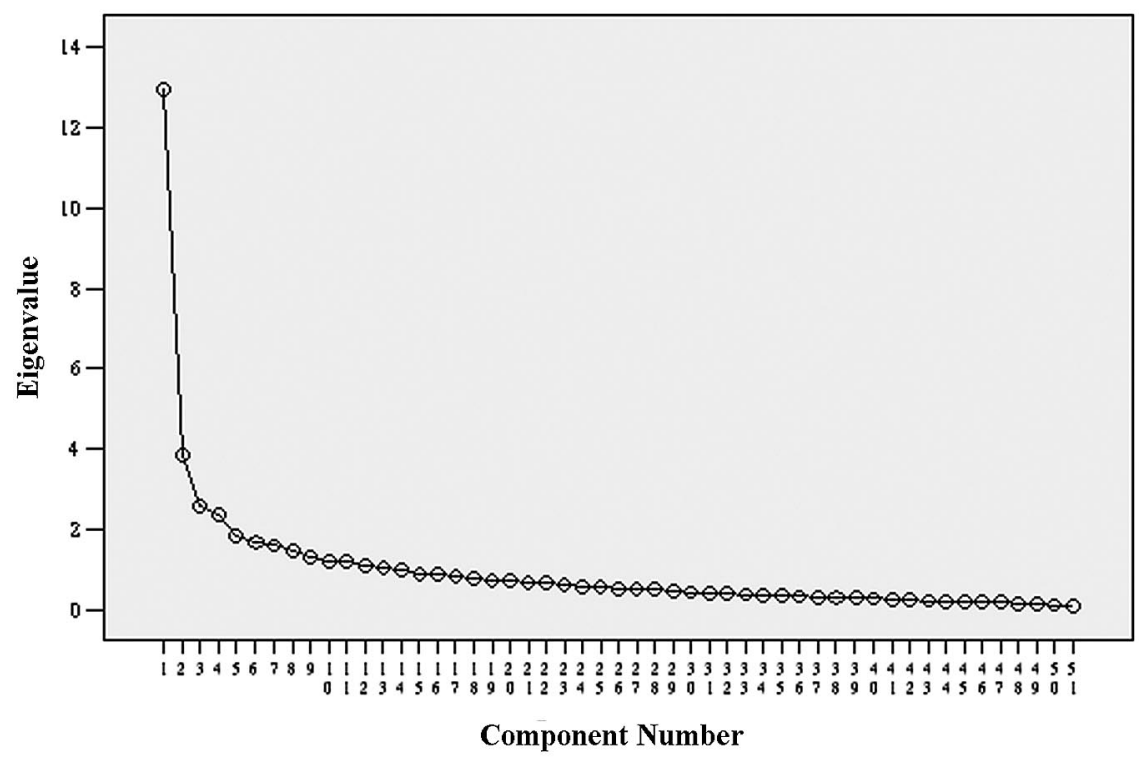

Fig. 2. Screen plot of the principal components of analysis of the COPD Self-Management Scale.

Table 1. Variance Explained by the 51-Item COPD SelfManagement Scale

\begin{tabular}{lrccc}
\hline \hline \multicolumn{1}{c}{ Domain } & $\begin{array}{c}\text { Number } \\
\text { of Items }\end{array}$ & $\begin{array}{c}\text { Domain } \\
\text { Loading }\end{array}$ & $\begin{array}{c}\text { \% of } \\
\text { Variance }\end{array}$ & $\begin{array}{c}\text { Cumulative } \\
\%\end{array}$ \\
\hline Symptom management & 8 & $0.45-0.77$ & 25.38 & 25.38 \\
Daily life management & 14 & $0.43-0.69$ & 7.51 & 32.89 \\
Emotion management & 12 & $0.46-0.74$ & 5.06 & 37.95 \\
Information management & 8 & $0.46-0.69$ & 4.62 & 42.57 \\
Self-efficacy & 9 & $0.44-0.63$ & 3.63 & 46.20 \\
\hline
\end{tabular}

Alpha values and item-total correlation were determined to evaluate the effects of item deletion. The initial principal components analysis yielded 16 factors with Eigenvalues $>1$. All 16 components accounted for $69.60 \%$ of the entire variance. Upon examining the scree plot (Fig. 2), a clear "elbow" was seen at 5 factors, which directed the subsequent analysis: solutions between 4 and 6 factors were examined. After examination of the 3 solutions, the 5 -factor solution was determined to be the best solution, because all of the loadings on factors were high $(>0.40)$ (Table 1), and there were fewer double loadings than the other solutions. Of the 56 items put to factor analysis, 51 items comprised the 5 factors, which explained $46.20 \%$ of the total variance. Based on the item contents, the 5 factors were named as the following domains: symptom management (8 items), daily life management (14 items), emotion management (12 items), information management (8 items), and self-efficacy (9 items) (see Table 1). The results fit the initial conceptual framework.

The construct validity of the 51-item CSMS was further assessed by correlation analysis of scores among items, domains, and the total scale. The item-total correlation coefficients of the domains varied between 0.45 and 0.85 . As shown in Table 2, the inter-domain correlation coefficients varied between 0.36 and 0.65 , and the domain-total correlation coefficients varied between 0.81 and 0.92 , confirming the construct validity of the scale.

The content validity index of the CSMS was 0.90 , which is higher than the standard proposed by Lynn for content validity index $(>0.78) .{ }^{14}$ The criterion validity of the scale is summarized in Table 3. The correlation coefficient of the total scores of the 51-item CSMS and the CSES was 0.71 . The CSMS self-efficacy domain was highly correlated with the total score of the CSES (correlation coefficient $=0.82$ ). Correlation between the CSMS domain scores and the total score of the CDSMBS ranged between 0.46 and 0.60 , and the correlation coefficient of the total scores of the 2 scales was 0.61 (see Table 3). The correlation coefficient of the total scores of the 51-item CSMS and the CDSES was 0.66. The CSMS self-efficacy domain was highly correlated with the total score of the CDSES (correlation coefficient $=0.76)($ see Table 3$)$. Moreover, the total score of the CSMS were negatively correlated with $\mathrm{FEV}_{1} \%$, with a correlation coefficient of -0.55 (see Table 3). The correlation coefficients of the CSMS symptom management and daily life management domains with $\mathrm{FEV}_{1} \%$ were -0.57 and -0.64 , respectively (see Table 3 ).

As shown in Table 4, the test-retest correlation coefficients of the CSMS domains ranged between 0.72 and 0.87, and the Cronbach alpha ranged between 0.82 and 0.92 . The test-retest correlation coefficient of the total score was 0.87 , and the Cronbach alpha was 0.92 , providing evidence that the 51-item CSMS was stable and reliable according to generally accepted criteria ${ }^{16}$ and if good re- 
Development and Validation of a COPD Self-Management Scale

Table 2. Inter-Domain and Total Score Correlations of the COPD Self-Management Scale $(n=413)$

\begin{tabular}{|c|c|c|c|c|c|c|}
\hline & $\begin{array}{c}\text { Symptom } \\
\text { Management }\end{array}$ & $\begin{array}{c}\text { Daily Life } \\
\text { Management }\end{array}$ & $\begin{array}{c}\text { Emotion } \\
\text { Management }\end{array}$ & $\begin{array}{l}\text { Information } \\
\text { Management }\end{array}$ & $\begin{array}{c}\text { Self- } \\
\text { Efficacy }\end{array}$ & Total \\
\hline Symptom management & 1.00 & & & & & \\
\hline Daily life management & $0.42 *$ & 1.00 & & & & \\
\hline Emotion management & $0.46^{*}$ & $0.51 *$ & 1.00 & & & \\
\hline Information management & $0.36^{*}$ & $0.56 *$ & $0.53 *$ & 1.00 & & \\
\hline Self-efficacy & $0.65^{*}$ & $0.56^{*}$ & $0.64 *$ & $0.53 *$ & 1.00 & \\
\hline Total & $0.92 *$ & $0.86^{*}$ & $0.81 *$ & $0.83 *$ & $084 *$ & 1.00 \\
\hline
\end{tabular}

Table 3. Correlations Between COPD Self-Management Scale and Other Chronic Disease Self Assessment Tools $(n=150)$

\begin{tabular}{|c|c|c|c|c|}
\hline \multirow{2}{*}{ CSMS domain } & \multicolumn{4}{|c|}{ Total Score } \\
\hline & CSES & CDSMBS & CDSES & $\mathrm{FEV}_{1} \%$ \\
\hline Symptom management & $0.33 *$ & $0.60 *$ & $0.25^{*}$ & $-0.57 *$ \\
\hline Daily life management & $0.29 *$ & $0.46^{*}$ & $0.20 \dagger$ & $-0.64 \dagger$ \\
\hline Emotion management & $0.57 *$ & $0.48 *$ & $0.61 *$ & $-0.18 *$ \\
\hline Information management & $0.35^{*}$ & $0.48^{*}$ & $0.58 *$ & $-0.29 *$ \\
\hline Self-efficacy & $0.82 *$ & $0.53 *$ & $0.76^{*}$ & $-0.25 *$ \\
\hline Total CSMS score & $0.71 *$ & $0.61 *$ & $0.66^{*}$ & $-0.55 *$ \\
\hline \multicolumn{5}{|c|}{$\begin{array}{l}* P<.01 . \\
\dagger P<.05 . \\
\text { CSMS = COPD Self-Management Scale } \\
\text { CSES = COPD Self-Efficacy Scale } \\
\text { CDSMBS = Chronic Disease Self-Management B } \\
\text { CDSES = Chronic Disease Self-Efficacy Scale } \\
\mathrm{FEV}_{1}=\text { forced expiratory volume in first second } \\
\mathrm{FEV}_{1} \%=\text { percent-of-predicted } \mathrm{FEV}_{1} \%\end{array}$} \\
\hline
\end{tabular}

Table 4. Three-Week Test-Retest Reliability and Cronbach Alpha Coefficients of the COPD Self-Management Scale

\begin{tabular}{lcc}
\hline \hline \multicolumn{1}{c}{ CSMS domain } & $\begin{array}{c}\text { Pearson } \\
\text { Correlation } \\
\text { Coefficient } \\
\text { for the 2 Tests* }\end{array}$ & $\begin{array}{c}\text { Cronbach } \\
\text { Alpha }\end{array}$ \\
\hline Total score & 0.87 & 0.92 \\
Symptom management & 0.72 & 0.83 \\
Daily life management & 0.87 & 0.86 \\
Emotion management & 0.84 & 0.87 \\
Information management & 0.78 & 0.82 \\
Self-efficacy & 0.76 & 0.83 \\
* All Pearson correlation coefficients $P<.01$. & & \\
\hline
\end{tabular}

liability is based on a test-retest correlation coefficient of $>0.7$ and a Cronbach alpha of $>0.8$.

\section{Discussion}

Although self-management reportedly can improve COPD patients' health and quality of life, there is no val- idated instrument for evaluating the status of patients' selfmanagement on COPD. To fill that gap, in the present study, we developed and validated a scale to assess COPD self-management. The 51-item CSMS showed good content, construct, and criterion validity, as well as test-retest reliability and internal consistency in a large sample of COPD subjects, including both in and out-patients. The CSMS items and scales were selected based on a comprehensive literature review and a concept analysis of the self-management behavior of patients with COPD. Our findings suggest that the CSMS captures multiple important domains of COPD self-management.

The results of factor analysis identified 5 CSMS domains, providing evidence in support of the conceptual framework. These factors accounted for $46.20 \%$ of the total variance, suggesting good construct validity. The reliability of the CSMS is supported by good internal consistency. The satisfactory levels of item-total and domain-total correlations suggest that the items are sufficiently related. With Cronbach alpha values between 0.87 and 0.92 , the CSMS's internal consistency was well above the minimum Cronbach alpha recommended for reliability $(>0.70) \cdot{ }^{17}$

As there is no standard reference measurement of COPD self-management, the test of criterion validity was difficult. Wigal et al developed the 34-item CSES to assess self-efficacy in COPD subjects. The CSES has good testretest reliability $(r=0.77)$, excellent internal consistency $($ Cronbach alpha $=0.95)$, and a 5 -factor structure (negative affect, intense emotional arousal, physical exertion, weather/environmental, and behavioral risk factors. ${ }^{9}$ Thus, this established CSES was used in the present study for the criterion test. An established questionnaire on chronic disease self-management, developed by Lorig et al, includes 4 primary classifications of outcome variables (health behaviors, health status, self-efficacy, and health service utilization), which enable a description of how well a patient manages chronic disease. ${ }^{10,11}$ The 4 subscales of 20 outcome variables are self-management behavior change, self-efficacy, health status, and health service utilization. The self-management behavior change and the self-effi- 


\section{Development and Validation of a COPD Self-Management Scale}

cacy subscales in the questionnaire were respectively employed as the CDSMBS and the CDSES in the present study for criterion tests. $\mathrm{FEV}_{1} \%$ is a widely used measure of COPD severity. ${ }^{18}$ The CSMS total score negatively correlated with $\mathrm{FEV}_{1} \%$, with a correlation coefficient of -0.55 . Particularly, the CSMS symptom management and daily life management domains had relatively high correlation coefficients with $\mathrm{FEV}_{1} \%$, indicating good criterion validity for the CSMS.

COPD is now well recognized as placing a heavy burden on patients and on the healthcare system. Numerous studies have demonstrated the benefits of self-management intervention for COPD. ${ }^{5-7}$ Efraimsson et al showed that self-care education could motivate COPD patients for lifestyle changes. ${ }^{5}$ Bourbeau et al demonstrated that selfmanagement intervention would be cost saving, relative to usual care, in COPD patients, thereby holding positive economic benefits. ${ }^{6}$ Nguyen et al reported that dyspnea self-management could help improve depression in COPD patients. ${ }^{7}$ However, there has been no dedicated scale for evaluating patients' self-management on COPD. The CSMS developed and validated in the present study is the first dedicated scale for evaluating the status of the selfmanagement of patients with COPD. Therefore, it may serve as an effective tool to assess the effects of various self-management interventions of patients with COPD, thereby helping change COPD patients' lifestyle, reducing costs of hospitalization, and improving patients' depression and quality of life. Nevertheless, as the CSMS was developed and validated only in the Hunan region of China, further studies need to evaluate its applicability to other ethnicities and countries.

\section{Conclusions}

In conclusion, the CSMS is a reliable, valid, and sensitive tool for evaluating the self-management status of patients with COPD. It will serve as an important instrument for assessing and improving the self-management of patients with COPD, at least in China.

\section{REFERENCES}

1. Rabe KF, Hurd S, Anzueto A, Barnes PJ, Buist SA, Calverley P, et al. Global strategy for the diagnosis, management, and prevention of chronic obstructive pulmonary disease: GOLD executive summary. Am J Respir Crit Care Med 2007;176(6):532-555.

2. Mathers CD, Loncar D. Projections of global mortality and burden of disease from 2002 to 2030. PLoS Med 2006;3(11):e442.

3. Halbert RJ, Natoli JL, Gano A, Badamgarav E, Buist AS, Mannino DM. Global burden of COPD: systematic review and meta-analysis. Eur Respir J 2006;28(3):523-532.

4. Zhong N, Wang C, Yao W, Chen P, Kang J, Huang S, et al. Prevalence of chronic obstructive pulmonary disease in China: a large, population-based survey. Am J Respir Crit Care Med 2007;176(11): 753-760.

5. Efraimsson EO, Hillervik C, Ehrenberg A. Effects of COPD selfcare management education at a nurse-led primary health care clinic. Scand J Caring Sci 2008;22(2):178-185.

6. Bourbeau J, Collet JP, Schwartzman K, Ducruet T, Nault D, Bradley C. Economic benefits of self-management education in COPD. Chest 2006;130(6):1704-1711.

7. Nguyen HQ, Carrieri-Kohlman V. Dyspnea self-management in patients with chronic obstructive pulmonary disease: moderating effects of depressed mood. Psychosomatics 2005;46(5):402-410.

8. GOLD Scientific Committee. Global strategy for the diagnosis, management and prevention of chronic obstructive pulmonary disease. 2004. http://www.goldcopd.org/Guidelines/guidelines-globalstrategy-for-diagnosis-management-2004-3.html. Accessed August 23, 2013.

9. Wigal JK, Creer TL, Kotses H. The COPD self-efficacy scale. Chest 1991;99(5):1193-1196.

10. Lorig K, Stewart A, Ritter P, Gonzalez V, Laurent D, Lynch J. Outcome measures for health education and other health care interventions. Thousand Oaks, CA: Sage Publications; 1996.

11. Fu D, Fu H, McGowan P, Shen YE, Zhu L, Yang H, et al. Implementation and quantitative evaluation of chronic disease self-management programme in Shanghai, China: randomized controlled trial. Bull World Health Organ 2003;81(3):174-182.

12. Corbin J, Straus A. Unending work and care: managing chronic illness at home. San Francisco: Jossey Bass; 1988.

13. Worth H, Dhein Y. Does patient education modify behaviour in the management of COPD? Patient Educ Couns 2004;52(3):267-270.

14. Lynn MR. Determination and quantification of content validity. Nurs Res 1986;35(6):382-385.

15. Kaiser HF. Index of factorial simplicity. Psychometrika 1974;39(1): 31-36.

16. Zhaojie Liu. Evaluation of reliability and validity of the questionnaire. Chin J Prev Control Chro Non-Commun Dis 1997;5(5):174177.

17. Polit DF, Beck CT. Nursing research: Principle and methods, 7th edition. New York: Lippincott William \& Wilkins; 2004.

18. Nathell L, Nathell M, Malmberg P, Larsson K. COPD diagnosis related to different guidelines and spirometry techniques. Respir Res 2007;8:89. 